\title{
A Rural Community in a Brazilian Western Amazonian Region: Some Demographic and Epidemiological Patterns
}

\author{
LMA Camargo, MM Moura*/*:, V Engracia*/**, RC Pagotto, SA Basano, \\ LH Pereira da Silva**:, EP Camargo, B Beiguelman, H Krieger $/^{+}$
}

\begin{abstract}
Departamento de Parasitologia, Instituto de Ciências Biomédicas, Universidade de São Paulo, Av. Lineu Prestes 1374 , 05508-900 São Paulo, SP, Brasil *Universidade Federal de Rondônia, Porto Velho, RO, Brasil **Centro de Pesquisa em Doenças Tropicais, Porto Velho, RO, Brasil

Some demographic and epidemiological patterns of the rural population of Monte Negro, locality situated in the State of Rondônia (Brazil), Western Amazonia, are described based on a sample of 924 randomly selected individuals, approximately $10 \%$ of the whole population. The main features of this sample are (1) the illiteracy rates in the parental generation were $23 \%$ for fathers and $20 \%$ for mothers. Among children, this figure dropped to 6\%; (2) housing in Monte Negro is characterized by being constructed with wood (92\%), and also a floor (75\%). Nevertheless, only $32 \%$ of these houses had electric energy; (3) the mean ages for the parental generation were 41.9 for males and 36.3 for females. These values for the offspring generation were 12.2 and 10.5, respectively; (4) the sexratio of the offspring generation was 1.32;(5) the bioassay of kinship was estimated as .033 for this long range migrant population; (6) the prevalence of some macrophage dependent infectious disease was conspicuously high; (7) the reported number of malarial episodes among males and females was statistically different, suggesting that malaria may be, in part, a "professional" disease; (8) the prevalence of serum-positive reactions against B-hepatitis is distressing. It has a strong age dependence and reaches $74 \%$ among adult males. Conversely, signs of active infection (AgHbs) rises to $16 \%$ among children.
\end{abstract}

Key words: demography - epidemiology - malaria - hepatitis - Western Amazonia - Rondônia - Brazil

Demography has well-known implications to population genetics and epidemiology. Migration, fertility, mortality, age distribution, among others, are some of the population characteristics that may be vital to the understanding of disease distribution in families, space and time and even may provide important clues to the pathogenesis of certain diseases.

The present report, which is part of a more comprehensive study of the infectious disease patterns in the Western Amazonian region (Camargo et al. 1994, 1996, 1999), intends to describe and analyze some of the population parameters of a mainly rural population, and to contribute to the understanding of the genetic epidemiology of some parasitic infections in this population, which may be applied to populations of other regions as well.

Locality and sampling - Monte Negro is a county of the State of Rondônia, Western Amazonian region $\left(10^{\circ} 15^{\prime} 35^{\prime \prime} \mathrm{S}, 63^{\circ} 18^{\prime} 06^{\prime \prime} \mathrm{W}\right)$ with about 13,000 inhabitants, most of them living in a rural economy, with small agricultural properties. It is known that most of the adult population is originated from southern Brazilian states, with some admixture with local populations, which arrived at Rondônia

Supported by Fapesp, CNPq, Pronex, Finep and Funasa. ${ }^{+}$Corresponding author. Fax: +55-11-3818.7417. E-mail: hkrieger@icb.usp.br

Received 5 April 2001

Accepted 10 September 2001 earlier, either at the beginning of the century, during the so called "rubber boom" or even earlier, like the Amerindian component of the present day ethnically admixed population.

During the year of 1998, a randomly selected sample of approximately $10 \%$ of the total population was collected to obtain genetic epidemiological data on some infectious diseases, with relatively high prevalence in the state. This sample was selected on the basis of a previous medicaldemographic compilation of all the houses in the municipality. This compilation has served for several epidemiologic inquiries and also for medical services to the community.

The sample includes 924 individuals and, due to its genetic interest, it is basically composed of nuclear families, with or without children. Very few families were not ascertained, due either to the fact that they moved to other localities or were temporarily out of their houses. These families were replaced by other nuclear families, either one house up or down, alternatively. There were no cases of familial refusal to cooperate.

On a pre-defined site of each "line" (a line being the name given to small roads perpendicular to the main axis of the federal freeway BR 421), the field team conducted medical examination of the local families, provided some specific medication when needed, and collected information, as well as blood samples. The field team was composed by, at least, one physician, nurses, health assistants and social workers. This research was approved by the "Medical Board of the State of Rondônia, Brazil" and 
an informed consent was obtained from all adults as well as from the parents or legal guardians of minors who participated in this present investigation.

Social factors - The population of Monte Negro is characterized by rather poor living conditions, but better to those observed three decades ago in other rural Brazilian populations, as measured by the type of housing, occupation and literacy (Krieger et al. 1965).

The main occupation of the great majority of fathers is concerned with agriculture (96\%), while the mothers' principal occupation is predominantly domestic (79\%), followed by agricultural activity (14\%).

Illiteracy is rather frequent among parents (23\% of fathers and $20 \%$ of mothers). This value decreases sharply among children (6\%), indicating a significant improvement in education conditions. This is also noticeable when the proportion of children (above 14 years of age) with secondary or upper education $(26 \%)$ is compared with their parents' equivalent proportions (13\% of fathers and $12 \%$ of mothers).

Houses in Monte Negro are building with local wood $(92 \%)$ and $75 \%$ have a floor. At the time of the survey only $32 \%$ of these houses had electric energy.

Age and sex composition - The mean age of the parental generation was $41.90 \pm 13.21$ for males and $36.30 \pm$ 13.35 for females, whereas for the offspring generation, it was $12.23 \pm 8.77$ for males and $10.46 \pm 7.37$ for females. When the sampled individuals were distributed according to age, it was observed a sharp decline of the frequencies with age. This is an indication that the population is exposed to both a strong selective environment, thus making rare the survival of relatively elder people, and to a somewhat high fertility rate, thus increasing the frequen- cies of the younger classes.

The sex ratio of the offspring generation is rather high (1.320), a conspicuous excess of males being observed even at the younger age groups. We do not have, at the moment, a tested explanation for this phenomenon.

Migration - When the parents and children of the present sample were classified according to their birthplaces, it became clear that for both males and females of the parental generation, the southern State of Paraná (27\%) contributed most, followed by Minas Gerais, a southeastern state $(\sim 20 \%)$. In contrast, only $11 \%$ and $4 \%$ of the children originated from these two states. The frequency of children born in the State of Rondônia (67\%) is much higher than that of the parental generation $(2 \%$ of the fathers and $7 \%$ of the mothers), which indicates that the older generation migrated at a relatively young age, below the mean reproductive age. It is possible to state that the Monte Negro population was formed chiefly by young long-range (more than $2,000 \mathrm{~km}$ ) migrants, that settled in Rondônia around 20 years ago.

Phenotype assay of kinship - Whalund (1928) was the first to observe that even when a population is subdivided in large isolates, the genetic effect of this subdivision will be an increase of the frequency of homozygotes, an effect that is similar to that provoked by consanguineous marriages. Since closely related individuals (kin) are likely to share many genes of common ancestry, it seems clear that Whalund's effect on human populations may be measured by an increase of their kinship coefficient $(\alpha)$. Eleven genetic polymorphisms were used to simultaneously estimate $\alpha$ and gene frequencies by Yasuda's method (1966), the maximum likelihood estimates are shown in Table I.

TABLE I

Estimated kinship coefficient and allele frequencies for six genetic systems in mother-father pairs of Monte Negro, State of Rondônia

\begin{tabular}{|c|c|c|c|c|c|c|c|}
\hline \multirow{2}{*}{$\frac{\text { System }}{\mathrm{ABO}}$} & \multicolumn{3}{|c|}{ Estimated allele frequencies (standard error) } & \multirow[t]{2}{*}{$\alpha$} & \multirow[t]{2}{*}{$\mathrm{K}_{\alpha \alpha}$} & \multirow[t]{2}{*}{$\chi^{2}$} & \multirow[t]{2}{*}{ d.f. } \\
\hline & $\mathrm{O}$ & A & $\mathrm{B}$ & & & & \\
\hline & $.6894(.0181)$ & $.2233(.0170)$ & $.0873(.0106)$ & $.4813 \mathrm{E}-2$ & $.1051 \mathrm{E}+5$ & $.4682 \mathrm{E}+1$ & 7 \\
\hline \multirow[t]{2}{*}{$\mathrm{MN}$} & M & $\mathrm{N}$ & & & & & \\
\hline & $.5437(.0193)$ & $.4563(.0193)$ & & $.1989 \mathrm{E}+2$ & $.9798 \mathrm{E}+3$ & $.2236 \mathrm{E}+1$ & 4 \\
\hline \multirow[t]{2}{*}{ Duffy } & $\mathrm{Fy}^{\mathrm{a}}$ & $\mathrm{Fy}$ & Fy- & & & & \\
\hline & $.3332(.0207)$ & $.4136(.0214)$ & $.2532(.0207)$ & $.2196 \mathrm{E}-1$ & $2993 \mathrm{E}+4$ & $.1216 \mathrm{E}+2$ & 7 \\
\hline \multirow[t]{2}{*}{ Kell } & $\mathrm{K}$ & $\mathrm{k}$ & & & & & \\
\hline & $.0126(.0042)$ & $.9874(.0042)$ & & $-.9466 \mathrm{E}+1$ & $.5631 \mathrm{E}+2$ & $.4359 \mathrm{E}+00$ & 1 \\
\hline \multirow[t]{2}{*}{ Hemoglobin } & A & $\mathrm{C}$ & $\mathrm{S}$ & & & & \\
\hline & $.9899(.0038)$ & $.0028(.0020)$ & $.0073(.0032)$ & $.1339 \mathrm{E}-1$ & $.3510+6$ & $.3767 \mathrm{E}+1$ & 2 \\
\hline \multirow[t]{2}{*}{ Haptoglobin } & 1 & 2 & & & & & \\
\hline & $.4604(.0239)$ & $.5396(.0239)$ & & $-.2560 \mathrm{E}+2$ & $.7776 \mathrm{E}+3$ & $.1241 \mathrm{E}+2$ & 4 \\
\hline Total & & & & $-.8439 \mathrm{E}-2$ & $.4112 \mathrm{E}+4$ & $.3569 \mathrm{E}+2$ & 25 \\
\hline Estimated alpha & & .0332 & & & & & \\
\hline Standard error & & .0156 & & & & & \\
\hline
\end{tabular}


In spite of the fact that this population is predominantly composed by long range migrants, its estimated kinship coefficient $(\alpha=.0332 \pm .0156)$ does not differ much from the value obtained by Yasuda (1969) in a northeastern Brazilian population with a much higher frequency of close inbreeding. Therefore, the present results confirm that, in practice, subdivision of populations is certainly the most important factor acting on departures from panmixia. Obviously, the type of migration may be an important cause in the increase of the kinship coefficient in Monte Negro, since when migration is not basically of unrelated male individuals, but of family groups, the kinship coefficient may rise instead of decrease. In fact, it is well known that immigrants who emigrated from the same region tend to maintain close relationship in the new settlement, which favor marriages among them.

Morbidity - An idea of the infectious morbidity profile of this population is here formulated by an account of the clinical findings of the more conspicuous diseases both by interview and by serological evidences. Among the several infectious diseases in Monte Negro, the prevalence of the macrophage dependent diseases was relatively high. Thus, the frequencies of visceromegalia, tegumentar leishmaniosis, leprosy, tuberculosis and profound mycosis among the parents were $4.1 \%, 13 \%, 2 \%$, $1.2 \%$ and $1.5 \%$, respectively. Among the children the frequencies of these diseases were $3.9 \%, 2.2 \%, 0.8 \%, 1 \%$ and $0.2 \%$, respectively. These data point to the pressing need of intra-dermal diagnosis of Leishmania and Mycobacteria infection, in order to better understand the dynamics of the infective process of these diseases and perhaps contribute to their prevention.

Table II show the reported number of malarial episodes in both generations, in Monte Negro. These distributions reflect, in part, the lack of precision of this information, but nevertheless provide some interesting indication. As can be seen, high number of malarial episodes is significantly more frequent among fathers than among mothers (Kruskal-Wallis' $\mathrm{H}=16.03$, d.f. $=1, \mathrm{P}<0.001$ ). This difference is mostly due to the higher frequency of fathers with 20 or more malarial episodes, and to the higher frequency of mothers with no antecedents of malaria. In fact, a very high chi-square is obtained $\left(\chi^{2}=12.196\right.$, d.f. $=1, \mathrm{P}<$ 0.001 ) when the analyzed sample is subdivided into two

TABLE II

Number of malarial episodes in Monte Negro, State of Rondônia

\begin{tabular}{lccr}
\hline No. & Father & Mother & Children \\
\hline 0 & $17(8.8 \%)$ & $37(18 . \%)$ & $211(42.3 \%)$ \\
$1-5$ & $82(42.3 \%)$ & $95(46.1 \%)$ & $206(41.3 \%)$ \\
$6-10$ & $24(12.4 \%)$ & $35(17 . \%)$ & $47(9.4 \%)$ \\
$11-20$ & $24(12.4 \%)$ & $17(8.3 \%)$ & $29(5.8 \%)$ \\
$\geq 20$ & $46(23.7 \%)$ & $22(10.7 \%)$ & $6(1.2 \%)$ \\
\hline Total & 193 & 206 & 499 \\
\hline
\end{tabular}

groups (less than 20 and 20 or more malarial episodes) for comparison. If the four groups with less than 20 malarial episodes are compared no significant differences among them are detected $\left(\chi^{2}=7.567\right.$, d.f. $\left.=3 ; \mathrm{P}>0.05\right)$. However, when these individuals are grouped into two classes (no episodes and 1-19 episodes), a significant sex difference emerges $\left(\chi^{2}=4.369\right.$, d.f. $\left.=1, \mathrm{P}<0.05\right)$. These results suggest that, at least in part, malaria is a "professional" disease, resembling the epidemiological profile observed in other regions of the state (Camargo et al. 1994, 1996), in contrast with the observations made in a riverine hamlet, where evidences of premonition were observed (Camargo et al. 1999). Another feature that can be observed is that the children's distribution has a significant shift to the left, indicating either a secular trend or the lack of sufficient exposure time.

Serology for hepatitis B showed some dramatic figures. The prevalence of serum-positive for $\mathrm{AgHbc}$ was $73.7 \%, 67.2 \%$ and $47.7 \%$ among fathers, mothers and children, respectively. Concerning the positive AgHbs (formerly called Australia antigen), the figures were $7.4 \%$, $5.3 \%$ and $16 \%$ for fathers, mothers and children, respectively. These data indicates that there is a sharp age difference, both for infection prevalence, and mainly for the presence of active disease. The puzzling high expectation of the presence of HVB virus antigen in very young ages challenges the epidemiologists to uncover all possible ways of catching the infective virus. The present results are, in a way similar to those reported by Fonseca et al. (1988) in the sense that there is a relatively high prevalence of healthy virus carriers, mainly among young people.

\section{REFERENCES}

Camargo LMA, Dal Colleto GMD, Ferreira MU, Gurgel SM, Escobar AL, Marques A, Krieger H, Camargo EP, Pereira da Silva LH 1996. Hypoendemic malaria in Rondônia (Brazil, Western Amazon region): seasonal variation and risk groups in an urban locality. Amer J Trop Med Hyg 55: 3238.

Camargo LMA, Ferreira MU, Krieger H, Camargo EP, Pereira da Silva LH 1994. Unstable hypoendemic malaria in Rondônia (Western Amazon region, Brazil): epidemic outbreaks and work-associated incidence in agro-industrial rural settlement. Amer J Trop Med Hyg 51: 16-25.

Camargo LMA, Noronha E, Salcedo JMV, Dutra AP, Krieger H, Pereira da Silva LH, Camargo EP 1999. The epidemiology of malaria in Rondônia (Western Amazon region, Brazil): study of a riverine population. Acta Trop 72: 1-11.

Fonseca JC, Simonetti SR, Schatzmayr HG, Castejon MJ, Cesario AL, Simonetti JP 1988. Prevalence of infection with hepatitis delta virus (HDV) among carriers of hepatitis B surface antigen in Amazonas State, Brazil. Trans $R$ Soc Trop Med Hyg 82: 469-471.

Krieger H, Morton NE, Mi MP, Azevêdo E, Freire-Maia A, Yasuda, N 1965. Racial admixture in northeastern Brazil. Ann Hum Genet 29: 113-125.

Yasuda N 1966. The Genetical Structure of Northeastern Brazil, PhD Thesis, Graduate School, University of Hawaii, USA, $232 \mathrm{pp}$.

Yasuda N 1969. The inbreeding coefficient in northeastern Brazil. Human Hered 19: 444-456. 
Amazonian Rural Community • LMA Camargo et al. 